\title{
Magnetic Resonance Imaging of the Cervical Spine: Frequency of Abnormal Findings with Relation to Age
}

\author{
Ali Alghamdi $1, * \mathbb{D}$ and Abeer Alqahtani ${ }^{2}$ \\ 1 Department of Radiological Sciences, Faculty of Applied Medical Sciences, University of Tabuk, \\ Tabuk 71491, Saudi Arabia \\ 2 Department of Radiology, King Fahad Hospital, Albaha 65515, Saudi Arabia; abeerzumaya@hotmail.com \\ * Correspondence: ah.alghamdi@ut.edu.sa
}

check for updates

Citation: Alghamdi, A.; Alqahtani, A. Magnetic Resonance Imaging of the Cervical Spine: Frequency of Abnormal Findings with Relation to Age. Medicines 2021, 8, 77. https:// doi.org/10.3390/medicines8120077

Academic Editor:

Abrar-Ahmad Zulfiqar

Received: 14 November 2021

Accepted: 10 December 2021

Published: 14 December 2021

Publisher's Note: MDPI stays neutral with regard to jurisdictional claims in published maps and institutional affiliations.

Copyright: (c) 2021 by the authors. Licensee MDPI, Basel, Switzerland. This article is an open access article distributed under the terms and conditions of the Creative Commons Attribution (CC BY) license (https:/ / creativecommons.org/licenses/by/ $4.0 /)$.

\begin{abstract}
Background: Patients with neck pain are frequently encountered in cervical spine (C-spine) magnetic resonance imaging (MRI) practice. However, the exact distribution and prevalence of cervical abnormalities are not known. Aim: The aim of this study is to evaluate the association between age, gender, and prevalence of abnormal cervical MRI findings. Methods: Records of 111 cervical MRIs were collected in 12 months from January to December 2019 from adults aged 20-89 years who were referred from neurosurgery, neurology, and orthopedic clinics. Findings were classified and analyzed using the Statistical Package for Social Science (SPSS), version 24.0 (IBM, Armonk, NY, USA). The chi-square test was used to determine the association between demographics and abnormalities using a significance of $p=0.05$. Results: The majority of patients were female (72.1\%). The number of abnormal incidences increased with age until it reached a peak at ages 50-59. Spondylodegenerative changes were the most frequent finding, which was present in $52.2 \%$ of the total sample, and was followed by disc bulge (25.2\%). Incidences increased in lower discs, with C5-C6 being the most frequent in 65\% of the total sample. Younger males in their 20 s had more injuries than females of the same age. However, this rate was reversed in patients over 40, as women were the dominant gender among patients in their 40 s with cervical injuries, with a rate of $81.5 \%$. Conclusion: In our study, we found that older patients developed more C-spine injuries. Gender may play a role in the rate of incidents. However, we did not find any significant differences between men and women or between different types of abnormalities.
\end{abstract}

Keywords: magnetic resonance imaging; cervical spine; age-related; findings

\section{Introduction}

Magnetic resonance imaging (MRI) is a noninvasive imaging technique that is usually used to investigate the potential causes of neck pain. Differences in MRI findings among people are expected to be associated with age, gender, and quality of life.

In the recent decades, there has been an increasing rate and cost of cervical spine surgeries [1]. A wide range of research about the epidemiology, management, morbidity and mortality of abnormal findings in the cervical spine has been added to the literature in the last few years [2-8]. Degenerative diseases in the cervical spine (C-spine) are the most common neurological disorders in the older population. The progress of these diseases may lead to different injuries, such as cervical spondylosis and disc herniation. The prevalence of degeneration in the spine in the geriatric population requires a comprehensive understanding of clinical history and physical examinations, which are beyond the scope of this study. Imaging findings can therefore be associated with these outcomes.

The relationship between degenerative changes seen in C-spine MRI and neck symptoms is still unclear [2-8]. It has been proven that degenerative findings in the C-spine in asymptomatic subjects are age dependent [6,9-12]. The number of patients with cervical spondylotic myelopathy has been shown to increase with age [9]. Incidences of spinal 
stenosis also increase in elderly patients [9]. Degenerative diseases sometimes present as normal aging variations [10].

Although plain radiography provides valuable information about the C-spine, advanced imaging, such as computed tomography (CT) and MRI, plays a crucial role in providing an accurate diagnosis. However, to avoid the high radiation dose of CT, MRI is a great choice. Several previous studies using plain radiography have established the normal morphology and kinematic behavior of the C-spine [3-6].

No studies in Saudi Arabia have evaluated the influence of age on MRI C-spine findings for either asymptomatic or symptomatic patients. The definition, classification, and association of C-spine injuries and diseases are of specific interest for providing comprehensive understanding regarding the risk factors of the most common injuries and diseases, especially regarding those preoperative cases. The purpose of this study is to investigate the association between age and abnormal findings in C-spine MRIs in nontraumatic adult patients who suffer neck pain.

\section{Methods}

\subsection{Patients}

This is a retrospective cross-sectional study. A total of 111 records of cervical MRIs for adult patients aged 20-89 years with neck pain were reviewed using a $1.5 \mathrm{~T}$ superconductive magnet for 12 months from 1 January 2019 to 30 December 2019. Patients commonly were referred from neurology, neurosurgery, or orthopedic clinics in King Fahad Hospital, which serves as the major public hospital in Al-Baha, Saudi Arabia. The majority of patients lived within the city limits of Al-Baha. The exclusion criteria included a history of coronal deformity, trauma, brain or spinal surgery, and MRI images with artefacts. Inclusion criteria included all outpatients with neck pain, and sensory or motor symptoms, such as numbness, motor weakness, clumsiness, or gait disturbance.

Age groups were classified based on decades (e.g., 20-29). Abnormal findings were classified according to different categories. For example, curvature status was divided into normal and straightened and the six locations of cervical abnormality in the vertebral discs were classified from cervical 1-cervical $2(\mathrm{C} 1-\mathrm{C} 2)$ to $\mathrm{C} 7-\mathrm{T} 1$.

\subsection{Ethical Approval}

Ethical approval was obtained from the institutional review board of the Scientific and Research Committee at King Fahad Hospital, Al-Baha (approval number KFHBAHA/17022021/7). MRI reports were analyzed by an expert consultant radiologist.

\subsection{Statistical Analysis}

The data were analyzed using Statistical Package for Social Science (SPSS, version 26, IBM Corp, Armonk, NY, USA). The chi-square test was used to evaluate differences in abnormal findings between different groups. We analyzed the association between findings and demographic data and how different findings are linked to each other-for example, how frequently disc bulge is associated with spinal cord compression and how much spinal cord compression would increase signal intensity ISI incidence. Statistical significance is considered as $p<0.05$.

\section{Results}

This study reviewed records of 111 patients who were referred to MRI for C-spine assessment. Of the total patients, males comprised $27.9 \%$ and females comprised $72.1 \%$. The distribution of patients according to age is shown in Table 1.

The number of cervical MRI cases increased gradually with age until it reached the most populated group at ages 50-59 $(n=41,36.9 \%)$, followed by the age group $40-49(n=27,24.3 \%)$, and then it dropped gradually until it reached the least number of patients at ages 80-89 $(n=3$, $2 \%$ ). Of the total patients, $54.1 \%$ reported a straightened C-spine. Our results show that a straightened C-spine was observed in about $55 \%$ of female patients and $52 \%$ of male patients. 
Table 1. Distribution of the sample according to gender.

\begin{tabular}{|c|c|c|c|c|c|}
\hline & & & \multicolumn{2}{|c|}{ Gender } & \multirow[b]{2}{*}{ Total } \\
\hline & & & Male & Female & \\
\hline \multirow{14}{*}{ Age } & \multirow{2}{*}{$20-29$} & Count & 4 & 2 & 6 \\
\hline & & $\%$ within age & $66.7 \%$ & $33.3 \%$ & $100.0 \%$ \\
\hline & \multirow{2}{*}{$30-39$} & Count & 6 & 4 & 10 \\
\hline & & $\%$ within age & $60.0 \%$ & $40.0 \%$ & $100.0 \%$ \\
\hline & \multirow{2}{*}{$40-49$} & Count & 5 & 22 & 27 \\
\hline & & $\%$ within age & $18.5 \%$ & $81.5 \%$ & $100.0 \%$ \\
\hline & \multirow{2}{*}{$50-59$} & Count & 10 & 31 & 41 \\
\hline & & $\%$ within age & $24.4 \%$ & $75.6 \%$ & $100.0 \%$ \\
\hline & \multirow{2}{*}{$60-69$} & Count & 5 & 14 & 19 \\
\hline & & $\%$ within age & $26.3 \%$ & $73.7 \%$ & $100.0 \%$ \\
\hline & \multirow{2}{*}{$70-79$} & Count & 0 & 5 & 5 \\
\hline & & $\%$ within age & $0.0 \%$ & $100.0 \%$ & $100.0 \%$ \\
\hline & \multirow{2}{*}{$80-89$} & Count & 1 & 2 & 3 \\
\hline & & $\%$ within age & $33.3 \%$ & $66.7 \%$ & $100.0 \%$ \\
\hline \multirow{2}{*}{\multicolumn{2}{|c|}{ Total }} & Count & 31 & 80 & 111 \\
\hline & & $\%$ within age & $27.9 \%$ & $72.1 \%$ & $100.0 \%$ \\
\hline
\end{tabular}

An abnormal (straightened) curvature increased with age gradually from the 20s until it reached its peak at the 50s (Figure 1). That is to say, among the overall patients with a straightened C-spine, there were only $8.3 \%$ aged $20-29$ and $36.7 \%$ aged $50-59$.

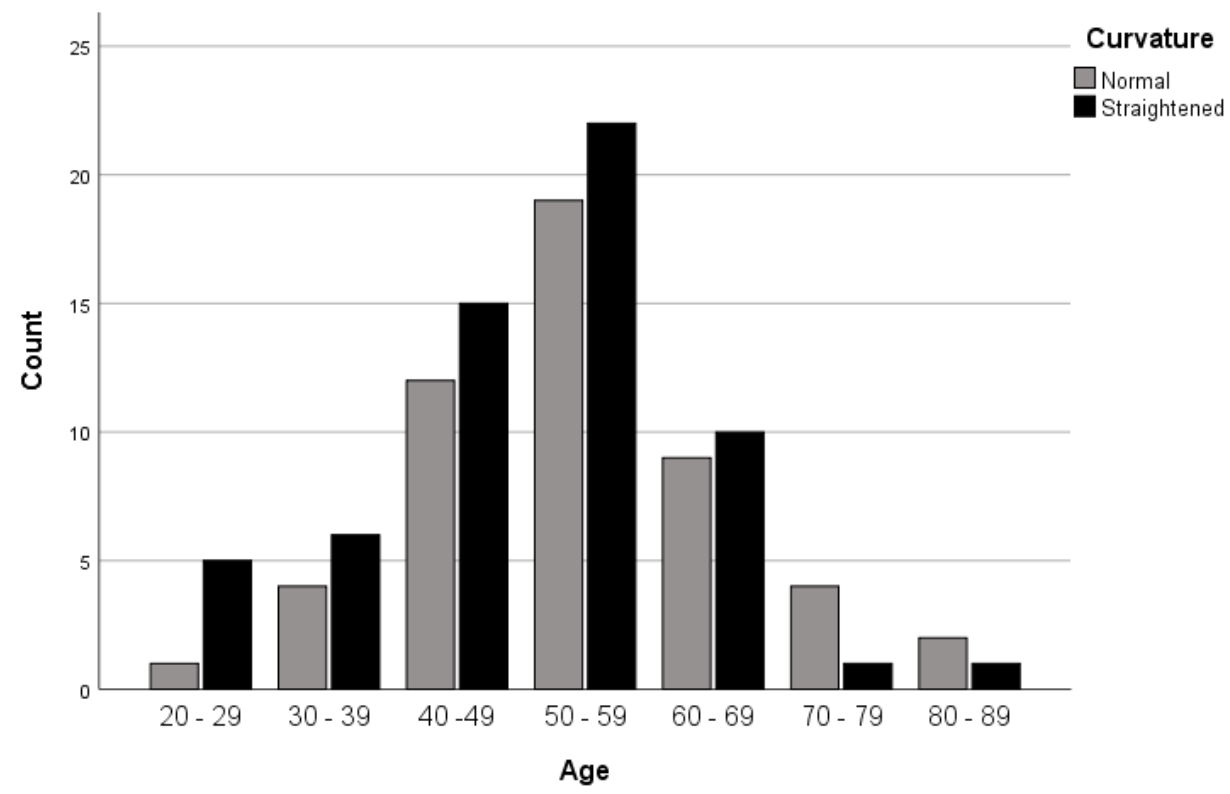

Figure 1. Prevalence of normal and straightened C-spine in different age groups.

The most frequent finding was spondylodegenerative changes (Table 2), which were present in $52.2 \%$ of patients, followed by disc protrusions and a disc bulge in $25.2 \%$ and $11.7 \%$ of patients, respectively. The least frequent abnormality was a burst fracture in $1.8 \%$ of cases. 
Table 2. Number of incidences.

\begin{tabular}{ccc}
\hline & Number & Percentage $\%$ \\
\hline Disc protrusions & 28 & 25.2 \\
\hline Disc bulge & 13 & 11.7 \\
\hline Mild spondylodegenerative changes & 58 & 52.3 \\
\hline Disc osteophytic complexes & 10 & 9 \\
\hline Burst fracture & 2 & 1.8 \\
\hline
\end{tabular}

Figure 2 shows the frequency of evidence according to vertebral discs in the C-spine. Our findings show that abnormalities increase gradually in lower discs until they reach the higher rates of $64 \%$ of patients with injuries in C5-C6. Then, the number of abnormalities drop gradually toward C6-C7.

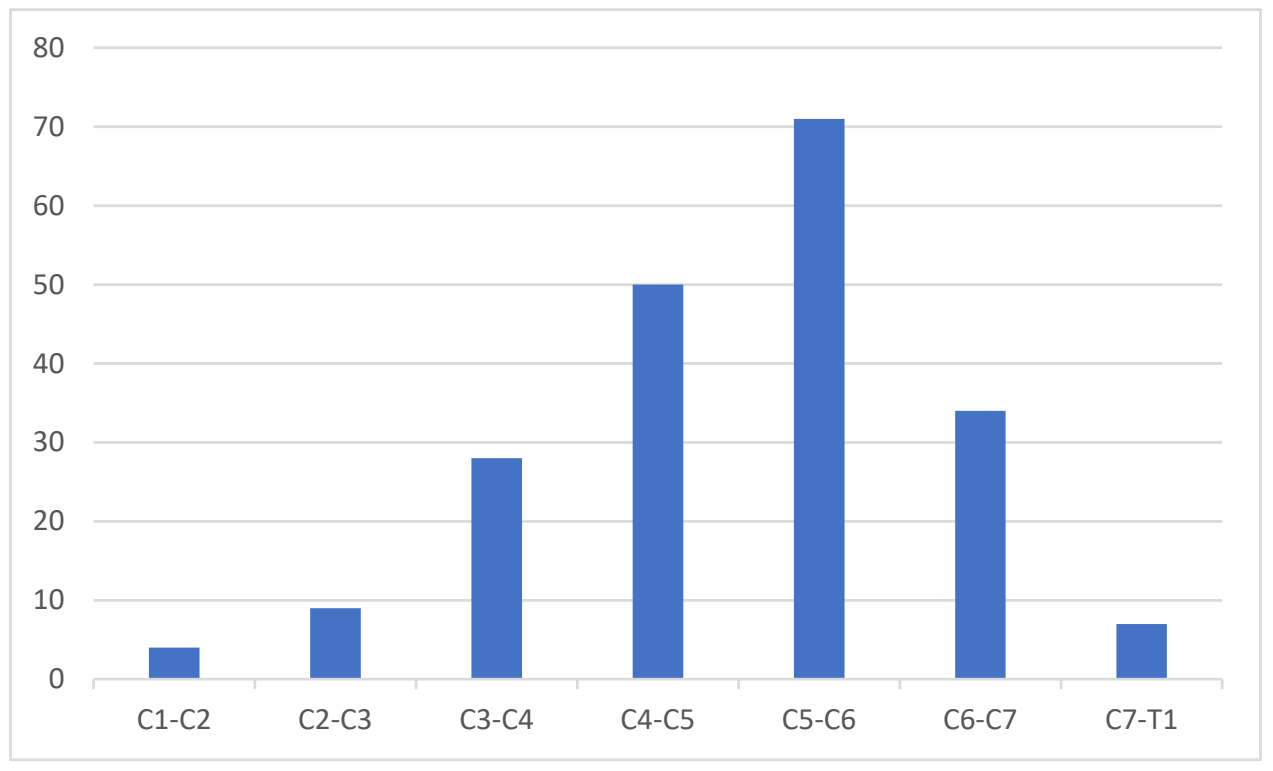

Figure 2. Most frequently injured cervical discs.

Figure 3 shows the frequency of cases according to the number of injured discs. The reviewed records show that most patients $(46 \%)$ had abnormalities in only one disc. Only three patients had injuries in all seven cervical discs.

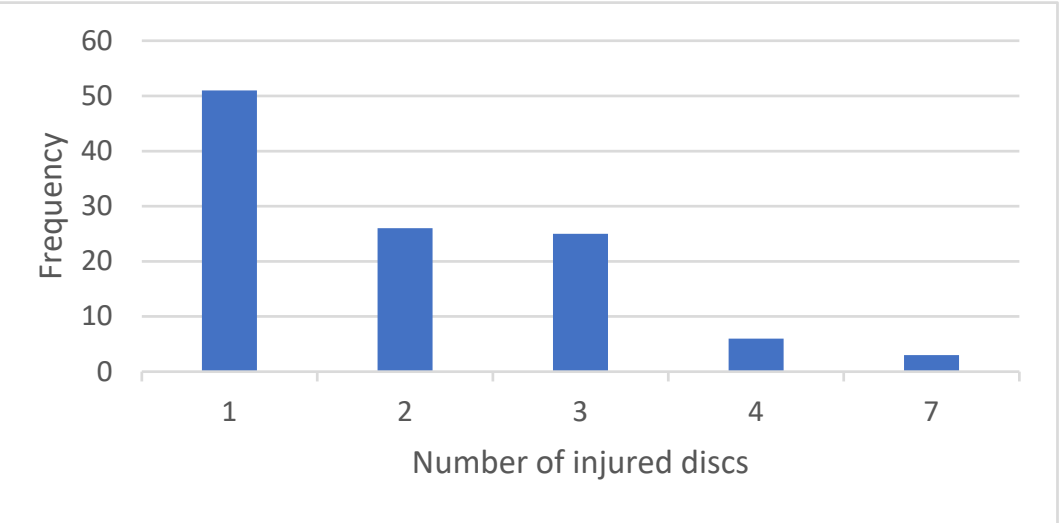

Figure 3. Number of injured discs in patients. 
The type of injury was significantly associated with age $(p=0.001)$. That is to say, $44.8 \%$ of patients with spondylodegenerative changes were aged $50-59$, and only $3.4 \%$ of patients aged 20-29 developed spondylodegenerative changes. Patients in the 40-49 age group comprised the highest rate of all patients with disc protrusions (43\%), followed by those aged 50-59 (21.4\%).

Surprisingly, abnormalities in different age groups were gender dependent $(p=0.043)$. In the younger groups, more male patients were observed (Figure 4). For example, 66.7\% of patients in the 20-29 age group were males and only 33.3\% were females. In addition, $60 \%$ of the 30-39 age group were males, while $40 \%$ were females. However, this rate was reversed in patients over 40 . That is to say, $81.5 \%$ of patients in the $40-49$ group were females, while only $18.5 \%$ were males; females comprised $75.6 \%$ of patients in the $50-59$ age group and only $24.4 \%$ were males; and females maintained higher rates compared to males in all older groups.

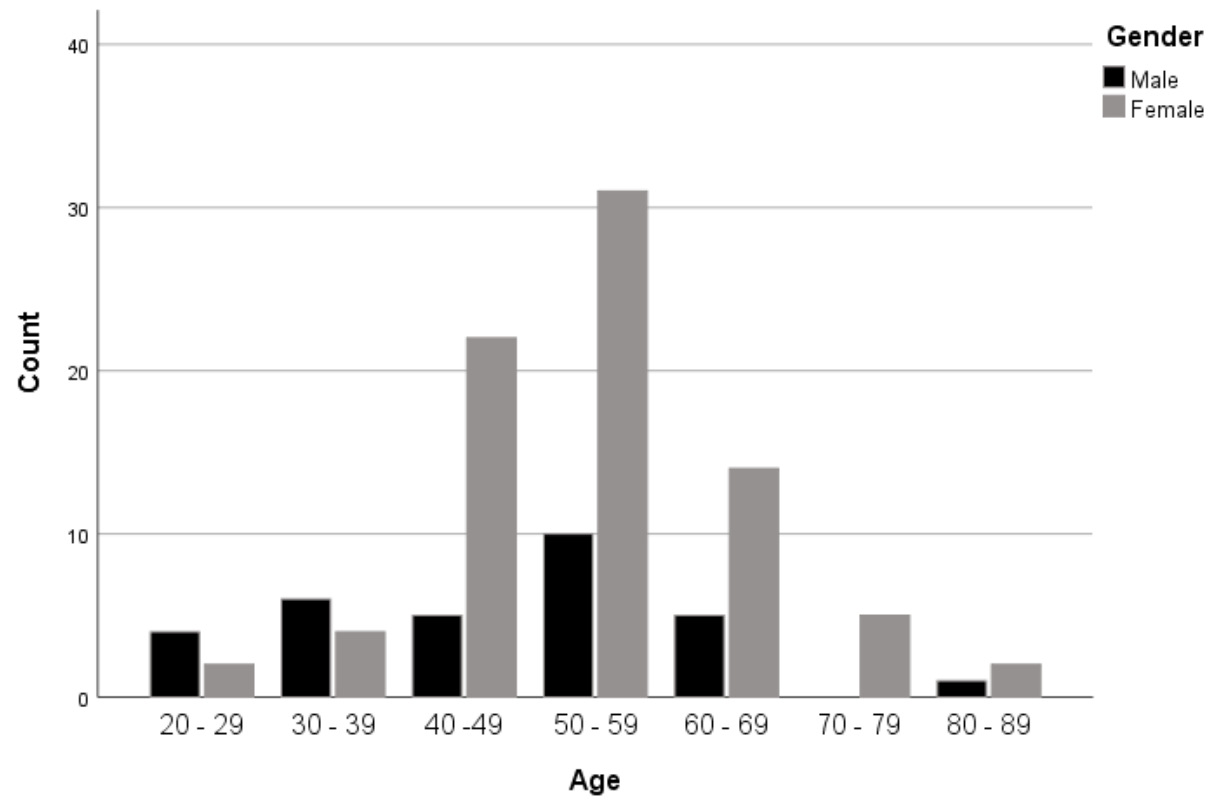

Figure 4. Distribution of gender in each age group.

\section{Discussion}

Understanding the association between age and the number of incidents of an abnormal C-spine can help more effective medical [11], surgical [12], and rehabilitative management [13]. To our knowledge, few studies have evaluated MRI findings of the $\mathrm{C}$-spine in relation to age. Evidence presented in our study indicates that, over a period of 12 months (between 1 January 2019 and 30 December 2019), abnormal MRI findings in the C-spine were significantly related to age.

Although abnormal C-spine curvature increased with age, no significant difference was observed between different age groups. In addition, no significant differences between male and female patients were observed. Our study showed that a majority of abnormal findings were found in female patients. Further study is required to investigate the factors influencing the incident rate in our study. This is consistent with previous studies that showed higher rates in female patients in the presence of different factors. For example, neck pain in female patients was significantly higher than that of male patients in the preceding 12 months of the radiographic examination. In addition, there was an association between degenerative changes and severity of neck pain in female patients [14]. This was supported by another study in which women more frequently exhibited thoracic (TX) and cervicothoracic junction (CTJ) pain with a wider lateral spread, regardless of disease status [15]. 
This was consistent with a previous study [16]. However, in that study, the authors found a significant difference in curvature profile between those over and under 40 years old. The authors suggested this may be due to age-related back muscle strength. One reason could be that, in the supine position, the physiological curvature becomes smaller than it is in the erect position [16]. An increase in cervical lordosis in both men and women has also been reported [17]. By contrast, Gote et al. found that cervical lordosis differed with age in men and women [18], as it appears earlier in men than in women.

In addition, although we found fewer abnormal findings in the higher vertebral levels, our findings show that vertebral disc abnormalities in the $\mathrm{C}$-spine were more frequent in the lower discs, with the most injured disc being C5-C6 (Figure 2). This could be due to increased pressure caused by weight on the lower discs. In relation to age, no disc bulging was observed in younger adults in their 20s. However, the rate of disc bulging (Figure 5) increased with age from the 20 s to a peak at the 50 s, as follows: $0 \%$ of the $20-29$ age group had a disc bulge, $7.7 \%$ among ages $30-39,23.1 \%$ among ages $40-49$, a peak of $38.5 \%$ among $50-59$, and then a drop in the older groups until it reached $0 \%$ among ages $80-89(p>0.05)$. The reason for the decreased cases of bulging disk with increased age could be due to the fact that a part of disc bulging cases resulted from physical injuries such as sport and motor vehicle injuries, which are increasing in younger ages worldwide [19]. Therefore, disc bulging decreases as the incidence of traumatic injuries decreases, which is the case in older population.

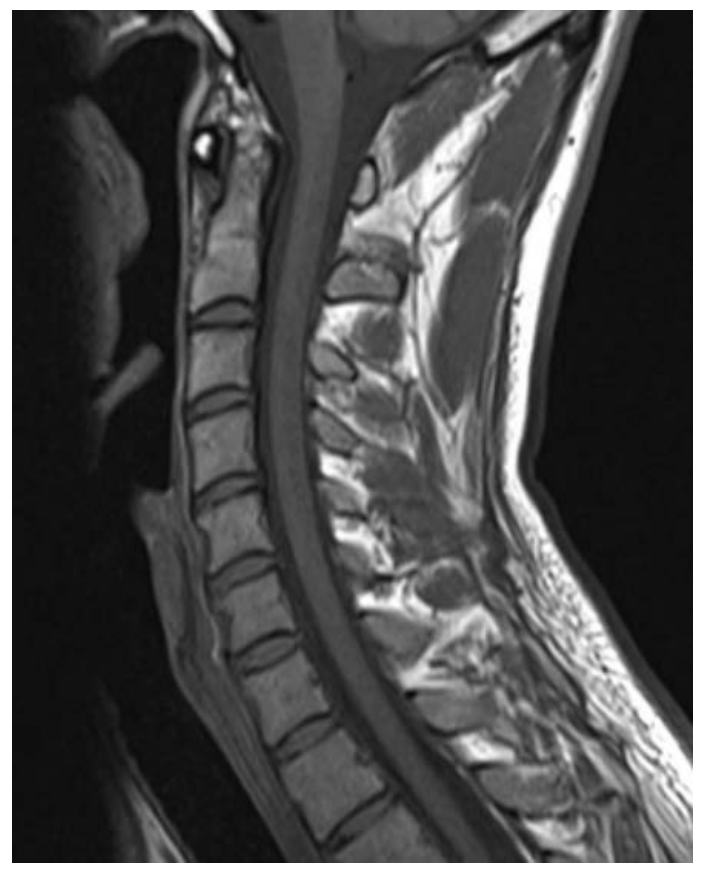

(A)

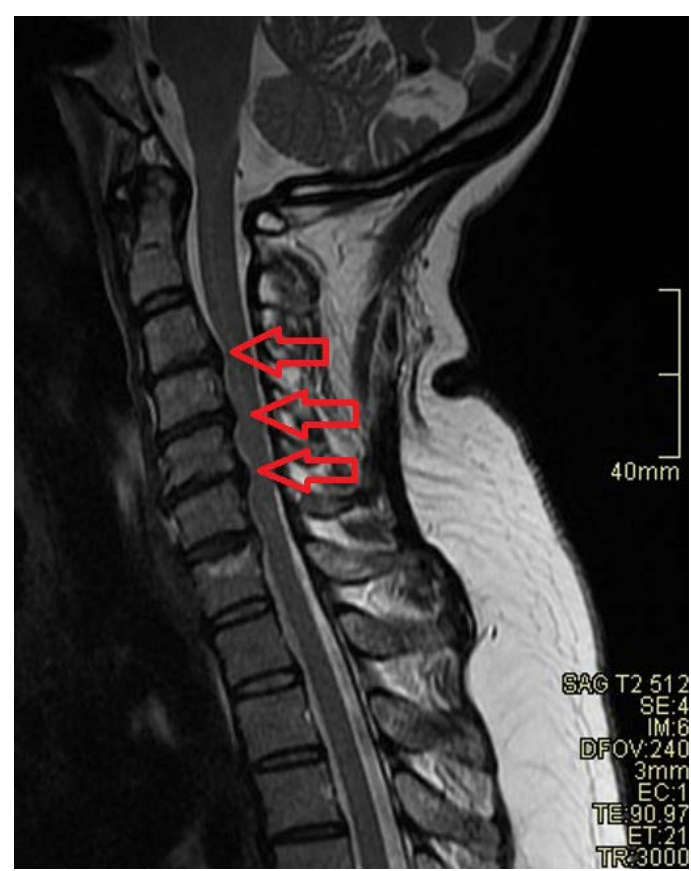

(B)

Figure 5. (A) Normal sagittal cervical spine T1 MRI; (B) 50 year old female patient with straightened cervical curvature is noted due to muscle spasm, in addition to advanced spondylodegenerative changes and multiple disc bulges (red arrows) of the cervical vertebrae. Reduced hydration of all cervical discs and sub end plate marrow degenerative changes in C3-C4, C4-C5 are also observed.

The increase of incidents of cervical disc bulging with age has been reported previously in asymptomatic patients [9,20-24]. The number of cases increased and reached a peak for the 50s age group. Disc bulging and protrusions occurred more frequently in lower levels.

It has been reported that age-related progressive changes in the intervertebral discs begin in the third decade of life [13]. Age-related physiological and pathological changes in the intervertebral discs have been outlined previously by Coventry et al. $[25,26]$. In some 
case, the intervertebral disc alterations are recognizable even to the naked eye [27]. However, MRI may be needed to detect signs of degeneration in asymptomatic persons [28,29].

Moreover, our results show that degenerative changes (Figure 6) in the C-spine were significantly age dependent $(p<0.05)$. For example, of the total patients with spondylodegenerative changes, $44.8 \%$ were in their sixth decade, and only $3.4 \%$ were in their third decade. This was consistent with a previous study conducted by Friedenberg and Miller [30], in which two large groups, one symptomatic and the other asymptomatic, were examined using $x$-rays of the spine. The authors observed degenerative changes in $75 \%$ of patients in their seventh decade and $25 \%$ of patients in their fifth decade. In both groups, the abnormalities were most frequent at the $\mathrm{C} 6-\mathrm{C} 7$ levels. The incidences of disc space narrowed at $\mathrm{C} 5-\mathrm{C} 6$ and were higher at $\mathrm{C} 6-\mathrm{C} 7$ in symptomatic patients [30]. A recent study reported that the age dependent degenerative changes of the cervical spine were more notable in females [31]. The effects of aging on the profile and alignment of the cervical spine have been recently reported [32,33].

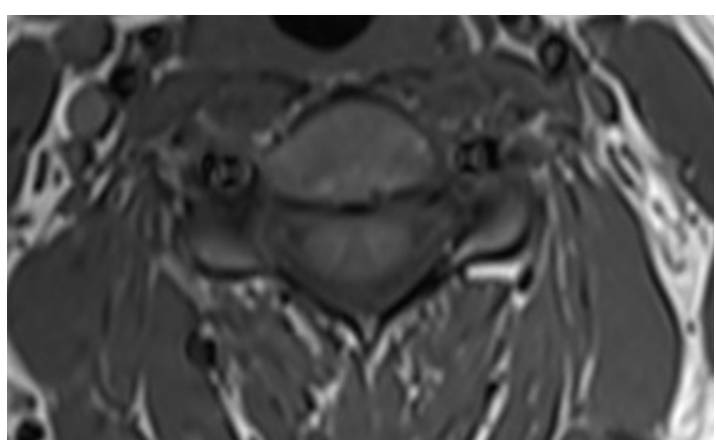

(A)

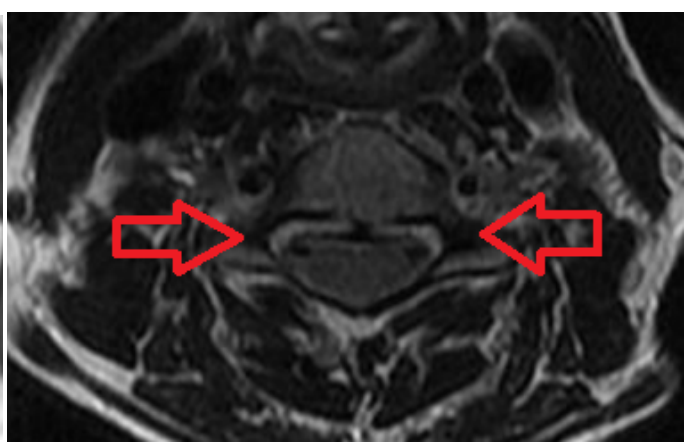

(B)

Figure 6. (A) Normal axial T1 MRI of cervical spine; (B) 57 year old female patient with C3-C4, C4-C5, C5-C6 and C6-C7 abnormalities: multiple levels of posterior disc osteophytic complexes indenting the ventral aspect of the subarachnoid space and encroaching upon neural foramina bilaterally at the corresponding levels.

There are several limitations to our study. First, it is a single-site study with a small sample size. Thus, a comprehensive study that includes several sites with a greater population is required to generate fuller results. Second, no information about quality of life or daily practices was collected. These factors may be associated with the degree of abnormal findings. In addition, MRI images were taken in the supine position, which is not a natural position of the spine. Therefore, $X$-rays could provide valuable information. Moreover, no follow-up was taken to assess the additional changes that may develop with aging. Therefore, a cohort study would provide valuable information about agerelated changes.

\section{Conclusions}

In our study, we have shown that younger male patients (in their 20s) are more prone to C-spine diseases than females of the same age, while older women (over 40) are more affected by the same diseases than men of the same age. Lower cervical discs are more frequently affected by disc diseases than higher vertebral discs. Abnormal findings also increase with age. However, we did not find any significant differences between men and women or between different types of abnormalities. This study provides valuable information about the distribution of abnormal findings of cervical spine MRI. This would be useful for MRI units and neurology clinics to set the best management of referral pattern, reduce waiting time and increase cost efficiency.

Author Contributions: Conceptualization, A.A. (Ali Alaghmdi) and A.A. (Abeer Alqahtani); methodology, A.A. (Ali Alaghmdi) and A.A. (Abeer Alqahtani); software, A.A. (Abeer Alqahtani); validation, A.A. (Ali Alaghmdi) and A.A. (Abeer Alqahtani); formal analysis, A.A. (Ali Alaghmdi); investigation, 
A.A. (Ali Alaghmdi) and A.A. (Abeer Alqahtani); resources, A.A. (Ali Alaghmdi); data curation, A.A. (Abeer Alqahtani); writing-original draft preparation, A.A. (Ali Alaghmdi); writing-review and editing, A.A. (Ali Alaghmdi); visualization, A.A. (Ali Alaghmdi) and A.A. (Abeer Alqahtani); supervision, A.A. (Ali Alaghmdi) and A.A. (Abeer Alqahtani); project administration, A.A. (Abeer Alqahtani). All authors have read and agreed to the published version of the manuscript.

Funding: This research received no external funding.

Institutional Review Board Statement: The study was conducted according to the guidelines of the Declaration of Helsinki, and approved by the Institutional Review Board at King Fahad Hospital, Al-Baha (approval number KFHBAHA/17022021/7) in 17 February 2021.

Informed Consent Statement: This is a retrospective study that dealt with data without direct interacting with patients.

Acknowledgments: We would like to thank the University of Tabuk and King Fahad Hospital in Al-Baha for their continued support.

Conflicts of Interest: The authors declare no conflict of interest.

\section{References}

1. Liu, C.Y.; Zygourakis, C.C.; Yoon, S.; Kliot, T.; Moriates, C.; Ratliff, J.; Dudley, R.A.; Gonzales, R.; Mummaneni, P.V.; Ames, C.P. Trends in Utilization and Cost of Cervical Spine Surgery Using the National Inpatient Sample Database, 2001 to 2013. Spine 2017, 42, E906-E913. [CrossRef]

2. Asemota, A.O.; Ahmed, A.K.; Purvis, T.E.; Passias, P.G.; Goodwin, C.R.; Sciubba, D.M. Analysis of Cervical Spine Injuries in Elderly Patients from 2001 to 2010 Using a Nationwide Database: Increasing Incidence, Overall Mortality, and Inpatient Hospital Charges. World Neurosurg. 2018, 120, e114-e130. [CrossRef]

3. Deckey, D.G.; Makovicka, J.L.; Chung, A.S.; Hassebrock, J.D.; Patel, K.A.; Tummala, S.V.; Chhabra, A. Neck and cervical spine injuries in National College Athletic Association athletes: A 5-year epidemiologic study. Spine 2020, 45, 55-64. [CrossRef]

4. Zaveri, G.; Das, G. Management of sub-axial cervical spine injuries. Indian J. Orthop. 2017, 51, 633-652. [CrossRef]

5. Meron, A.; McMullen, C.; Laker, S.R.; Currie, D.; Comstock, R.D. Epidemiology of cervical spine injuries in high school athletes over a ten-year period. PMER 2018, 10, 365-372.

6. Bokhari, A.R.; Sivakumar, B.; Sefton, A.; Lin, J.; Smith, M.M.; Gray, R.; Hartin, N. Morbidity and mortality in cervical spine injuries in the elderly. ANZ J. Surg. 2018, 89, 412-417. [CrossRef] [PubMed]

7. Cazzola, D.; Holsgrove, T.; Preatoni, E.; Gill, H.; Trewartha, G. Cervical Spine Injuries: A Whole-Body Musculoskeletal Model for the Analysis of Spinal Loading. PLoS ONE 2017, 12, e0169329. [CrossRef]

8. Page, P.S.; Wei, Z.; Brooks, N.P. Motorcycle helmets and cervical spine injuries: A 5-year experience at a Level 1 trauma center. J. Neurosurg. Spine 2018, 28, 607-611. [CrossRef] [PubMed]

9. Kato, F.; Yukawa, Y.; Suda, K.; Yamagata, M.; Ueta, T. Normal morphology, age-related changes and abnormal findings of the cervical spine. Part II: Magnetic resonance imaging of over 1,200 asymptomatic subjects. Eur. Spine J. 2012, 21, 1499-1507. [CrossRef] [PubMed]

10. Okada, E.; Matsumoto, M.; Ichihara, D.; Chiba, K.; Toyama, Y.; Fujiwara, H.; Momoshima, S.; Nishiwaki, Y.; Hashimoto, T.; Ogawa, J.; et al. Does the sagittal alignment of the cervical spine have an impact on disk degeneration? Minimum 10-year follow-up of asymptomatic volunteers. Eur. Spine J. 2009, 18, 1644-1651. [CrossRef] [PubMed]

11. Vale, F.L.; Burns, J.; Jackson, A.B.; Hadley, M.N. Combined medical and surgical treatment after acute spinal cord injury: Results of a prospective pilot study to assess the merits of aggressive medical resuscitation and blood pressure management. J. Neurosurg. 1997, 87, 239-246. [CrossRef] [PubMed]

12. Aarabi, B.; Olexa, J.; Chryssikos, T.; Galvagno, S.M.; Hersh, D.; Wessell, A.; Sansur, C.; Schwartzbauer, G.; Crandall, K.; Shanmuganathan, K.; et al. Extent of Spinal Cord Decompression in Motor Complete (American Spinal Injury Association Impairment Scale Grades A and B) Traumatic Spinal Cord Injury Patients: Post-Operative Magnetic Resonance Imaging Analysis of Standard Operative Approaches. J. Neurotrauma 2019, 36, 862-876. [CrossRef]

13. Jain, N.B.; Ayers, G.D.; Peterson, E.N.; Harris, M.B.; Morse, L.; O'Connor, K.C.; Garshick, E. Traumatic spinal cord injury in the United States, 1993-2012. JAMA 2015, 313, 2236-2243. [CrossRef]

14. Kumagai, G.; Ono, A.; Numasawa, T.; Wada, K.; Inoue, R.; Iwasaki, H.; Ishibashi, Y.; Iwane, K.; Matsuzaka, M.; Takahashi, I.; et al. Association between roentgenographic findings of the cervical spine and neck symptoms in a Japanese community population. J. Orthop. Sci. 2014, 19, 390-397. [CrossRef]

15. Swinnen, T.W.; Westhovens, R.; Dankaerts, W.; De Vlam, K. Widespread pain in axial spondyloarthritis: Clinical importance and gender differences. Arthritis Res. 2018, 20, 156. [CrossRef]

16. Liu, J.; Liu, P.; Ma, Z.; Mou, J.; Wang, Z.; Sun, D.; Cheng, J.; Zhang, D.; Xiao, J. The effects of aging on the profile of the cervical spine. Medicine 2019, 98, e14425. [CrossRef] 
17. Cote, P.; Cassidy, J.D.; Yong-Hing, K.; Sibley, J.; Loewy, J. Apophysial joint degeneration, disc degeneration, and sagittal curve of the cervical spine. Can they be measured reliably on radiographs? Spine 1997, 22, 859-864. [CrossRef]

18. Gore, D.R.; Sepic, S.B.; Gardner, G.M. Roentgenographic Findings of the Cervical Spine in Asymptomatic People. Spine 1986, 11, 521-524. [CrossRef] [PubMed]

19. Fehlings, M.G.; Singh, A.; Tetreault, L.; Kalsi-Ryan, S.; Nouri, A. Global prevalence and incidence of traumatic spinal cord injury. Clin. Epidemiol. 2014, 6, 309-331. [CrossRef] [PubMed]

20. Okada, E.; Matsumoto, M.; Fujiwara, H.; Toyama, Y. Disc degeneration of cervical spine on MRI in patients with lumbar disc herniation: Comparison study with asymptomatic volunteers. Eur. Spine J. 2010, 20, 585-591. [CrossRef]

21. Siivola, S.M.; Levoska, S.; Tervonen, O.; Ilkko, E.; Vanharanta, H.; Keinänen-Kiukaanniemi, S. MRI changes of cervical spine in asymptomatic and symptomatic young adults. Eur. Spine J. 2002, 11, 358-363. [CrossRef]

22. Matsumoto, M.; Okada, E.; Ichihara, D.; Watanabe, K.; Chiba, K.; Toyama, Y.; Fujiwara, H.; Momoshima, S.; Nishiwaki, Y.; Hashimoto, T.; et al. Age-Related Changes of Thoracic and Cervical Intervertebral Discs in Asymptomatic Subjects. Spine 2010, 35, 1359-1364. [CrossRef]

23. Boden, S.D.; McCowin, P.R.; Davis, D.O.; Dina, T.S.; Mark, A.S.; Wiesel, S. Abnormal magnetic-resonance scans of the cervical spine in asymptomatic subjects. A prospective investigation. J. Bone Jt. Surg.-Am. Vol. 1990, 72, 1178-1184. [CrossRef]

24. Schellhas, K.P.; Smith, M.D.; Gundry, C.R.; Pollei, S.R. Cervical discogenic pain: Prospective correlation of magnetic resonance imaging and discography in asymptomatic subjects and pain sufferers. Spine 1996, 21, 300-311. [CrossRef]

25. Aarabi, B.; Simard, J.M.; Kufera, J.A.; Alexander, M.; Zacherl, K.M.; Mirvis, S.E.; Shanmuganathan, K.; Schwartzbauer, G.; Maulucci, C.; Slavin, J.; et al. Intramedullary lesion expansion on magnetic resonance imaging in patients with motor complete cervical spinal cord injury. J. Neurosurg. Spine 2012, 17, 243-250. [CrossRef] [PubMed]

26. Simard, J.M.; Woo, S.K.; Norenberg, M.D.; Tosun, C.; Chen, Z.; Ivanova, S.; Tsymbalyuk, O.; Bryan, J.; Landsman, D.; Gerzanich, V. Brief Suppression of Abcc8 Prevents Autodestruction of Spinal Cord after Trauma. Sci. Transl. Med. 2010, 2, 28ra29. [CrossRef] [PubMed]

27. Aarabi, B.; Albrecht, J.S.; Simard, J.M.; Chryssikos, T.; Schwartzbauer, G.; Sansur, C.A.; Crandall, K.; Gertner, M.; Howie, B.; Wessell, A.; et al. Trends in Demographics and Markers of Injury Severity in Traumatic Cervical Spinal Cord Injury. J. Neurotrauma 2021, 38, 756-764. [CrossRef] [PubMed]

28. Chen, Y.; He, Y.; DeVivo, M.J. Changing Demographics and Injury Profile of New Traumatic Spinal Cord Injuries in the United States, 1972-2014. Arch. Phys. Med. Rehabil. 2016, 97, 1610-1619. [CrossRef] [PubMed]

29. McCaughey, E.J.; Purcell, M.; McLean, A.N.; Fraser, M.H.; Bewick, A.; Borotkanics, R.J.; Allan, D.B. Changing demographics of spinal cord injury over a 20-year period: A longitudinal population-based study in Scotland. Spinal Cord 2015, 54, 270-276. [CrossRef]

30. Friedenberg, Z.B.; Miller, W.T. Degenerative Disc Disease Of The Cervical Spine. J. Bone Jt. Surg. Am. 1963, 45, 1171-1178. [CrossRef]

31. Wang, X.-R.; Kwok, T.C.Y.; Griffith, J.F.; Yu, B.W.M.; Leung, J.C.S.; Wáng, Y.X.J. Prevalence of cervical spine degenerative changes in elderly population and its weak association with aging, neck pain, and osteoporosis. Ann. Transl. Med. 2019, 7, 486. [CrossRef]

32. Yokoyama, K.; Kawanishi, M.; Yamada, M.; Tanaka, H.; Ito, Y.; Kawabata, S.; Kuroiwa, T. Age-related variations in global spinal alignment and sagittal balance in asymptomatic Japanese adults. Neurol. Res. 2017, 39, 414-418. [CrossRef] [PubMed]

33. Chen, Y.; Luo, J.; Pan, Z.; Zhiyun, L.; Pang, L.; Zhong, J.; Li, Z.; Cao, K. The change of cervical spine alignment along with aging in asymptomatic population: A preliminary analysis. Eur. Spine J. 2017, 26, 2363-2371. [CrossRef] [PubMed] 